\title{
The distribution and accumulation of fucoxanthin and its metabolites after oral administration in mice
}

\author{
Takashi Hashimoto ${ }^{1}$, Yoshiaki Ozaki ${ }^{1}$, Mayuko Taminato ${ }^{1}$, Swadesh K. Das ${ }^{1}$, Masashi Mizuno ${ }^{1}$, \\ Kazuto Yoshimura ${ }^{1}$, Takashi Maoka ${ }^{2}$ and Kazuki Kanazawa ${ }^{1}$ \\ ${ }^{1}$ Graduate School of Agricultural Science, Kobe University, 1-1 Rokkodai, Nada, Kobe, Hyogo 657-8501, Japan \\ ${ }^{2}$ Research Institute for Production Development, 15 Shimogamo-morimoto, Sakyo, Kyoto 606-0805, Japan
}

(Received 17 July 2008 - Revised 27 October 2008 - Accepted 5 November 2008 - First published online 28 January 2009)

The pharmacokinetics of dietary fucoxanthin, one of the xanthophylls in brown sea algae, is little understood. In the present study, mice were orally administered fucoxanthin, and the distribution and accumulation of fucoxanthin and its metabolites fucoxanthinol and amarouciaxanthin A were measured in the plasma, erythrocytes, liver, lung, kidney, heart, spleen and adipose tissue. In a single oral administration of $160 \mathrm{nmol}$ fucoxanthin, fucoxanthinol and amarouciaxanthin A were detectable in all specimens tested in the present study, but fucoxanthin was not. The time at maximum concentration $\left(\mathrm{T}_{\max }\right.$ ) of these metabolites in adipose tissue was $24 \mathrm{~h}$, while the $\mathrm{T}_{\max }$ in the others was $4 \mathrm{~h}$. The area under the curve to infinity $\left(\mathrm{AUC}_{\infty}\right)$ of fucoxanthinol in the liver was the highest value $(4680 \mathrm{nmol} / \mathrm{g} \times \mathrm{h})$ among the tissues tested in the present study, while the $\mathrm{AUC}_{\infty}$ of amarouciaxanthin $\mathrm{A}$ in adipose tissue was the highest value $(4630 \mathrm{nmol} / \mathrm{g} \times \mathrm{h})$. In daily oral administration of $160 \mathrm{nmol}$ fucoxanthin for 1 week, fucoxanthin was also detectable in the tissues even at a low concentration. The amount of fucoxanthinol was $123 \mathrm{nmol} / \mathrm{g}$ in the heart and $85.2 \mathrm{nmol} / \mathrm{g}$ in the liver. Amarouciaxanthin $\mathrm{A}$ in the adipose tissue was distributed at a concentration of $97.5 \mathrm{nmol} / \mathrm{g}$. These results demonstrate that dietary fucoxanthin accumulates in the heart and liver as fucoxanthinol and in adipose tissue as amarouciaxanthin A.

Fucoxanthin: Fucoxanthinol: Amarouciaxanthin A: Mice

Brown algae are a traditional foodstuff of East Asians, and an epidemiological study ${ }^{(1)}$ has shown that the consumption of brown sea algae is associated with a low risk of breast cancer. Brown alga powders or extracts have been reported to suppress chemical-induced carcinogenesis in animals ${ }^{(2-5)}$. Fucoxanthin is one of the xanthophylls found in brown algae such as kombu (Laminaria japonica), hijiki (Sargassum fusiforme) and wakame (Undaria pinnatifida) ${ }^{(6)}$. The oral administration of fucoxanthin prevented carcinogenesis in several animal models ${ }^{(7,8)}$. Recent studies with cancer cell lines have suggested that the suppressive effect is due to the inhibitory effect of fucoxanthin on cell proliferation through the induction of apoptosis ${ }^{(9,10)}$ and cell cycle arrest ${ }^{(11)}$. In addition to these activities, the compound also has anti-inflammatory and anti-obesity activities ${ }^{(12,13)}$. Interestingly, a recent study showed that dietary fucoxanthin stimulates the expression of uncoupling protein 1 in the mitochondria of white adipose tissue and facilitates the consumption of fats in rats ${ }^{(14)}$. Thus, fucoxanthin has various physiological activities and contributes to the beneficial effects of brown algae.

Many studies ${ }^{(15-20)}$ have reported the metabolism of hydrocarbon carotenoids such as $\alpha$-carotene and $\beta$-carotene; these carotenoids are absorbed in the small intestine and then converted to vitamin A. However, information on the metabolism of non-provitamin A-type carotenoids is insufficient to explain their bioavailability and safety, although some xanthophylls such as astaxanthin and canthaxanthin have had their metabolism and accumulation reported ${ }^{(21-24)}$. Recent studies suggested that dietary fucoxanthin is hydrolysed to fucoxanthinol in the gastrointestinal tract by digestive enzymes such as lipase and cholesterol esterase, absorbed in the intestinal cells ${ }^{(25)}$, and then converted to amarouciaxanthin $\mathrm{A}$ in the liver ${ }^{(26)}$ (Fig. 1). Fucoxanthinol was detectable at $0.8 \mathrm{pmol} / \mathrm{ml}$ in human plasma after a daily intake of stirfried wakame $(6 \mathrm{~g}$ dry weight) including $6.1 \mathrm{mg}(9.26 \mu \mathrm{mol})$ of fucoxanthin for 1 week $^{(27)}$. These reports showed the mechanisms of absorption and metabolism of dietary fucoxanthin, but did not explain the bioavailability of fucoxanthin.

In the present study, the distribution and accumulation of fucoxanthin and its metabolites were investigated in mice orally administered with fucoxanthin once or daily for 1 week.

\section{Experimental methods}

Reagents

Pancreas lipase type II, lysophosphatidylcholine (1-palmitoyl$s n$-glycero-3-phosphocholine), mono-olein (glycerol $\alpha$-mono-

Abbreviations: $\mathrm{AUC}_{\infty}$, area under the curve to infinity; $\lambda_{\max }$, maximum wavelength; $\mathrm{T}_{\max }$, time at maximum concentration.

* Corresponding author: Dr Takashi Hashimoto, fax +81 78803 6553, email takashi@kobe-u.ac.jp 


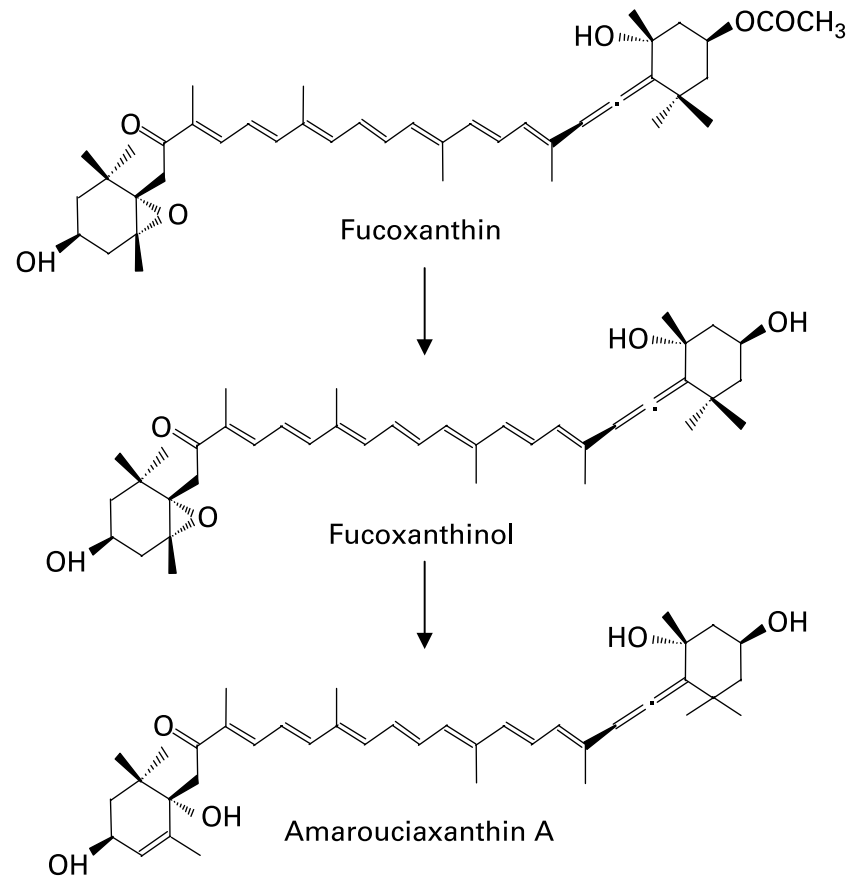

Fig. 1. The chemical structures of fucoxanthin, fucoxanthinol and amarouciaxanthin A.

oleate), taurocholic acid sodium salt hydrate and 3-(4, 5-dimethylthiazol-2-yl)-2,5-diphenyl were purchased from Sigma Chemicals (St Louis, MO, USA). Astaxanthin was purchased from Extrasynthèse (Genay, France). All other reagents were of the highest grade commercially available.

\section{Preparation of fucoxanthin, fucoxanthinol and amarouciaxanthin A}

Kombu (L. japonica) cultured in Hokkaido, Japan was harvested and extracted with ten volumes of absolute ethanol. After the extract was evaporated to remove the ethanol, the residue was extracted again with ethyl acetate and subjected to a silica gel column chromatography with a Wakogel C-100 (Wako Pure Chemical Industries, Osaka, Japan) eluted with hexane-ethyl acetate $(1: 1, \mathrm{v} / \mathrm{v})$ as a mobile phase. The orange-coloured phase that was rich in fucoxanthin was collected and dried by an evaporator. The dried matter was dissolved in $95 \%$ methanol and was then subjected to a preparative HPLC equipped with a Capcell pak C18 UG80 column $(250 \mathrm{~mm} \times 10 \mathrm{~mm}$ internal diameter, $5 \mu \mathrm{m}$; Shiseido, Tokyo, Japan) and a guard column $(10 \mathrm{~mm} \times 4.0 \mathrm{~mm}$ internal diameter). The fucoxanthin was collected by elution with $95 \%$ methanol and was monitored with a Hitachi L-7420 detector (Hitachi, Tokyo, Japan) at a wavelength of $450 \mathrm{~nm}$. Fucoxanthin was eluted at 16 min of the retention time. The fucoxanthin was $>99 \%$ purity as determined by the peak area and molecular extinction coefficient. The prepared fucoxanthin showed a molecular extinction coefficient (ethanol) $E_{1 \mathrm{~cm}} 1 \%$ of 1280 at maximum wavelength $\left(\lambda_{\max }\right) 448 \mathrm{~nm}$, while the published fucoxanthin value in ethanol is lower by $10 \%$ $\left(E_{1 \mathrm{~cm}}^{1 \%}=1140^{(28)}\right)$.

The fucoxanthinol was prepared from fucoxanthin by hydrolysis as described previously ${ }^{(25)}$ with a slight modification. In brief, $2 \mathrm{mg}$ fucoxanthin were mixed with $10 \mathrm{mg}$ taurocholic acid sodium salt hydrate in $1 \mathrm{ml}$ methanol and dried under a stream of $\mathrm{N}_{2}$ gas. The residue was dissolved in $8 \mathrm{ml} 0 \cdot 1 \mathrm{M}$-potassium phosphate buffer containing $20 \mathrm{mg}$ of porcine pancreas lipase type II at $\mathrm{pH} 7.0$ and incubated at $37^{\circ} \mathrm{C}$ for $2 \mathrm{~h}$. The lipase reaction was stopped by the addition of $1 \mathrm{ml}$ methanol. Fucoxanthinol was extracted with $2 \mathrm{ml}$ diethyl ether, and the diethyl ether was dried by an evaporator. The dried matter was dissolved in $95 \%$ methanol and was then subjected to preparative HPLC as well as purification of fucoxanthin as described above to purify the fucoxanthinol. Fucoxanthinol was eluted at $12 \mathrm{~min}$ of the retention time. The fucoxanthinol was $>99 \%$ purity as determined by the peak area and molecular extinction coefficient. The $\lambda_{\max }$ of fucoxanthinol in ethanol was $449 \mathrm{~nm}\left(E_{1 \mathrm{~cm}}^{1 \%}=1760\right)$.

Amarouciaxanthin A was purified from the tunicate Amaroucium pliciferum as described previously ${ }^{(29)}$, and identified by NMR and MS analyses.

\section{Preparation of mixed micelles containing fucoxanthin}

A mixed micelle containing fucoxanthin was prepared as described previously ${ }^{(26)}$. In brief, $1.58 \mathrm{mg}$ fucoxanthin was dissolved in $500 \mu \mathrm{l}$ ethanol with $19.4 \mathrm{mg}$ taurocholic acid sodium salt hydrate and was then dried under a stream of $\mathrm{N}_{2}$ gas. The residue was added to $1 \mathrm{ml} 3.75 \mathrm{~mm}$-lysophosphatidylcholine, $300 \mu \mathrm{l} 25 \mathrm{~mm}$-mono-olein, $300 \mu \mathrm{l} 75 \mathrm{~mm}$-oleic acid and $1.4 \mathrm{ml}$ distilled water and was agitated by a vortex mixer for $1 \mathrm{~min}$. This mixture was used as the mixed micelle comprising $0.8 \mathrm{mM}$-fucoxanthin, $12 \mathrm{mM}$-sodium taurocholate, 2.5 mM-mono-olein, $7.5 \mathrm{~mm}$-oleic acid and $1.25 \mathrm{~mm}$-lysophosphatidylcholine for oral administration to mice.

\section{Animals}

All animal treatments were approved by the Institutional Animal Care and Use Committee (permission numbers 19-5-17 and 19-5-19) and were carried out according to the Guidelines on Animal Experimentation of Kobe University. Male Imprinting Control Region (ICR) mice (aged 7 weeks; Japan SLC, Shizuoka, Japan) were acclimatised at $23^{\circ} \mathrm{C}$ with a $12 \mathrm{~h}$ light-dark cycle for 1 week and were allowed ad libitum access to food (Rodent Lab EQ 5L37; Japan SLC) and drinking water.

In the experiment with a single administration, the mice were fasted for $12 \mathrm{~h}$ and then administered with $200 \mu \mathrm{l}$ of mixed micelles including $160 \mathrm{nmol}(0.105 \mathrm{mg})$ of fucoxanthin intragastrically. After being anaesthetised with Nembutal (Dainippon Sumitomo Pharma, Osaka, Japan), the animals were killed 1, 2, 3, 4, 6, 9, 12, 24, 48 and $72 \mathrm{~h}$ after the administrations. The control mice at the $0 \mathrm{~h}$ time point were not orally administered anything but were anaesthetised.

In the experiment with a daily administration for 1 week, the mice were daily administered with $200 \mu$ l mixed micelle including $160 \mathrm{nmol}$ fucoxanthin for $7 \mathrm{~d}$ intragastrically, and were anaesthetised $24 \mathrm{~h}$ after the final administration. The control mice were orally administered with mixed micelle without fucoxanthin as a vehicle.

The blood was collected by cardiac puncture in a heparinised syringe and was centrifuged at $1000 \mathrm{~g}$ for $10 \mathrm{~min}$ at $4^{\circ} \mathrm{C}$. The supernatant fraction and precipitant are referred to 
as the plasma and erythrocytes, respectively. The liver was removed and immediately perfused with $\mathrm{PBS}$ and then frozen by liquid $\mathrm{N}_{2}$. The lung, kidney, heart, spleen and intraperitoneal adipose tissues were removed and immediately frozen by liquid $\mathrm{N}_{2}$. These were stored at $-80^{\circ} \mathrm{C}$ until use.

\section{High-performance liquid chromatography analysis of fucoxanthin and its metabolites}

The erythrocytes were washed twice with a 3-fold volume of PBS. The plasma and erythrocytes were added to $10 \mu \mathrm{l}$ $5 \mu \mathrm{M}$-astaxanthin as an internal standard. The plasma was diluted with a 3-fold volume of PBS, and the erythrocytes were diluted with a 2-fold volume of PBS. A sample (approximately $300 \mathrm{mg}$ ) of the tissue specimens was also mixed with $10 \mu \mathrm{l} 5 \mu \mathrm{M}$-astaxanthin and homogenised in a 9-fold volume of PBS. A sample $(800 \mu \mathrm{l})$ of the diluted plasma, diluted erythrocytes, or tissue homogenate was mixed with $600 \mu \mathrm{l}$ distilled water and $1.5 \mathrm{ml}$ dichloromethane-methanol $(1: 2, \mathrm{v} / \mathrm{v})$. They were extracted with $3.0 \mathrm{ml}$ dichloromethane three times, and the dichloromethane layer was collected after centrifugation at $1500 \mathrm{~g}$ for $15 \mathrm{~min}$. After evaporation, the residue from the dichloromethane layers was dissolved in a mixed solvent of dimethyl sulfoxide-methanol $(1: 1, \mathrm{v} / \mathrm{v})$, and a $50 \mu \mathrm{l}$ sample was subjected to HPLC analysis. A HPLC system equipped with an L-7420 detector was employed. The column $(250 \mathrm{~mm} \times 4.6 \mathrm{~mm}$ internal diameter) and a guard column $(10 \times 4.0 \mathrm{~mm}$ internal diameter) were of the Capcell pak C18 UG80 (Shiseido, Tokyo, Japan) and were maintained at $35^{\circ} \mathrm{C}$. Gradient elution was performed with solution $\mathrm{A}$, which was composed of methanol-0.3\% (w/v) ammonium acetate $(\mathrm{pH} 3 \cdot 0)(7: 3, \mathrm{v} /$ $\mathrm{v}$ ), and solution $\mathrm{B}$, which comprised $100 \%$ methanol delivered at a flow rate of $1.0 \mathrm{ml} / \mathrm{min}$ as follows: initially $80 \%$ of solution $\mathrm{A}$, and then 80 to $0 \%$ of $\mathrm{A}$ for $25 \mathrm{~min}$. Fucoxanthin, fucoxanthinol and amarouciaxanthin A were monitored at a wavelength of $450 \mathrm{~nm}$ and their peak area was determined. The amounts of fucoxanthin, fucoxanthinol and amarouciaxanthin A were calculated using calibration curves constructed with purified fucoxanthin, fucoxanthinol and amarouciaxanthin A.

\section{Pharmacokinetic and statistical analysis}

The pharmacokinetic parameters of fucoxanthin and its metabolites were calculated from their concentration time course using a non-compartmental pharmacokinetic analysis pro$\operatorname{gram}^{(30)}$

\section{Results}

Time-dependent changes in the levels of fucoxanthin and its metabolites after a single oral administration

To understand the time-dependent changes in the levels of fucoxanthin and its metabolites in tissues, mice were given a single oral administration of mixed micelle containing $160 \mathrm{nmol}(0.105 \mathrm{mg})$ of fucoxanthin. Fucoxanthin and its metabolites were measured in the blood and tissues $1,2,3$, $4,6,9,12,24,48$ and $72 \mathrm{~h}$ after the administration. Figure 2 showed the representative HPLC chromatogram of the

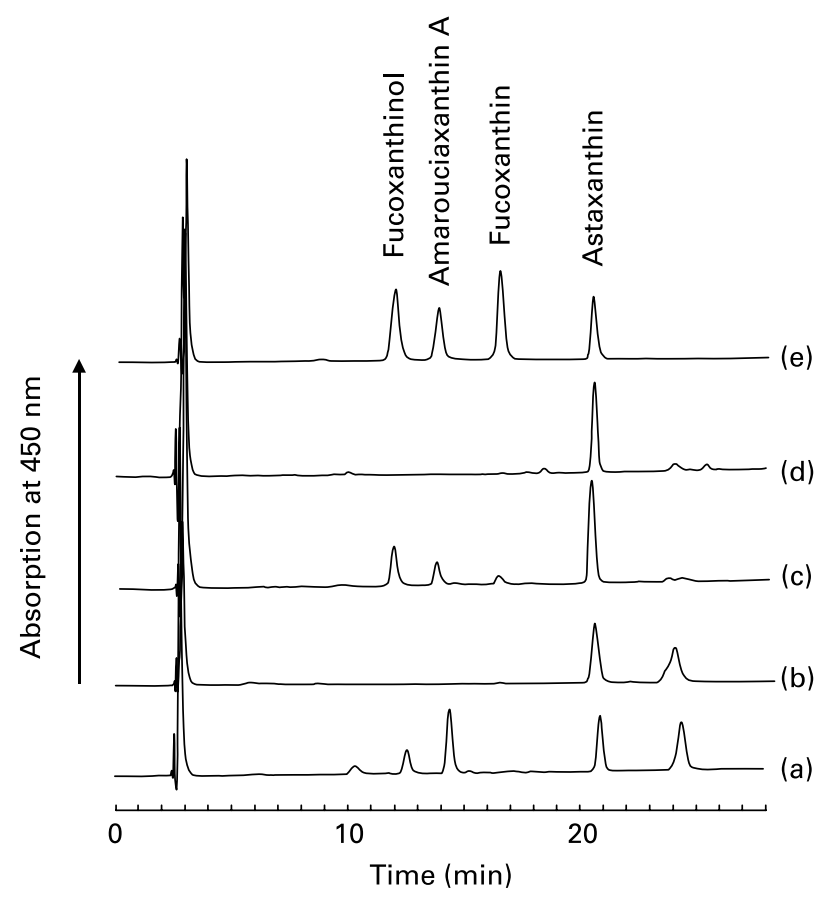

Fig. 2. Representative HPLC chromatograms of fucoxanthin and its metabolites in plasma and liver. The HPLC analysis was performed as described in Experimental methods. Chromatograms of the extract from the plasma $4 \mathrm{~h}$ after a single oral administration of fucoxanthin-containing micelles (a) and micelles only (b). Chromatograms of the extract from the liver of mice daily administered fucoxanthin-containing micelles (c) and micelles only (d). Chromatogram of the standards fucoxanthinol (retention time, $11.9 \mathrm{~min})$, amarouciaxanthin $A(13.8 \mathrm{~min})$, fucoxanthin $(16.4 \mathrm{~min})$ and astaxanthin (20.4 min) (e). Astaxanthin was used as an internal standard.

extract from the plasma of mice $4 \mathrm{~h}$ after administration. The peaks at 11.9 and 13.8 min completely fitted the peaks corresponding to the standards for fucoxanthinol and amarouciaxanthin A, respectively, when the extract mixed with these standards was injected into the HPLC (data not shown). On the other hand, fucoxanthin was undetectable in any tissues tested in the present study or in the blood. Except for in the adipose tissue, fucoxanthinol and amarouciaxanthin A increased until $4 \mathrm{~h}$ after administration and then decreased gradually until $24 \mathrm{~h}$ (Fig. 3). They were undetectable $48 \mathrm{~h}$ after administration (data not shown). Although the concentration of the metabolites in the adipose tissue also increased until $4 \mathrm{~h}$ and then decreased as in the other tissues, the concentration increased again, reached its maximum at $24 \mathrm{~h}$ after the administration, and the metabolites were still detectable at 72 h (Fig. 3).

The pharmacokinetic parameters were calculated from these data (Fig. 3) and are shown in Tables 1 and 2. The time at maximum concentration $\left(\mathrm{T}_{\max }\right)$ in the adipose tissue was $24 \mathrm{~h}$, while those in the other tissues were all $4 \mathrm{~h}$ (Table 2). The liver showed the highest values $(584$ and $190 \mathrm{nmol} / \mathrm{g}$ ) for the maximum concentration $\left(\mathrm{C}_{\max }\right)$ of fucoxanthinol and amarouciaxanthin $\mathrm{A}$, respectively, among the tissues tested in the present study (Table 2). The adipose tissue showed the lowest values $(38.8$ and $83.7 \mathrm{nmol} / \mathrm{g})$ for the $\mathrm{C}_{\max }$ of fucoxanthinol and amarouciaxanthin $\mathrm{A}$, respectively, among the tissues tested in the present study (Table 2). The area under the curve to infinity $\left(\mathrm{AUC}_{\infty}\right)$ of fucoxanthinol in the 

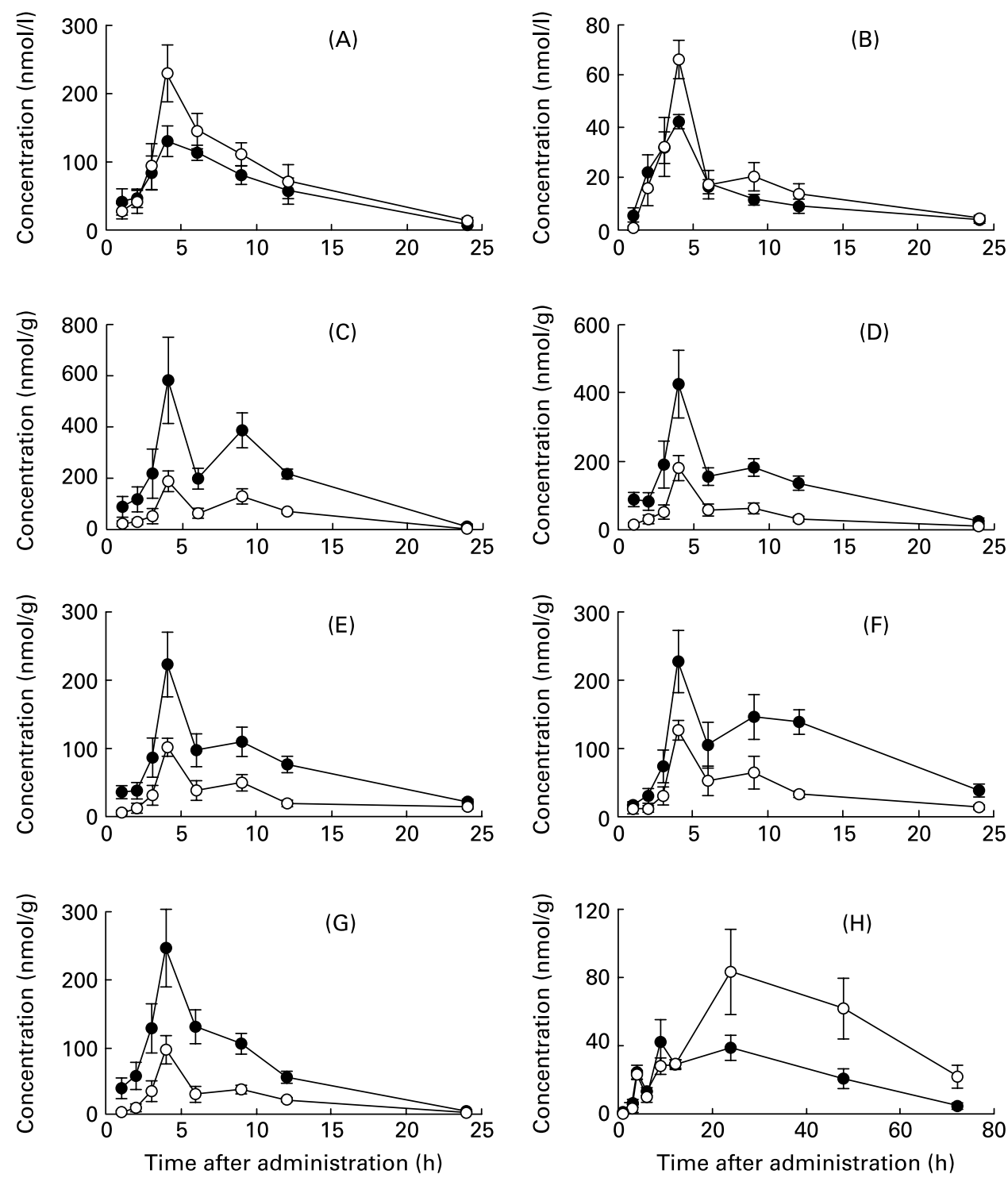

Fig. 3. Time profiles of fucoxanthinol $(\bullet)$ and amarouciaxanthin $A(O)$ after a single oral administration of fucoxanthin. Mice were orally administered with mixed micelles containing fucoxanthin (160 nmol/mouse). The concentration of fucoxanthinol and amarouciaxanthin $A$ in the plasma (A), erythrocytes (B) and tissues (liver $(C)$, lung $(D)$, kidney $(E)$, heart $(F)$, spleen $(G)$ and adipose tissue $(H)$ ) was determined by HPLC as described in Experimental methods. Values are means ( $n$ 6), with standard errors represented by vertical bars.

liver was the highest value $(4680 \mathrm{nmol} / \mathrm{g} \times \mathrm{h})$ among the tissues tested in the present study (Table 2), while the $\mathrm{AUC}_{\infty}$ of amarouciaxanthin $\mathrm{A}$ in the adipose tissue was the highest value $(4630 \mathrm{nmol} / \mathrm{g} \times \mathrm{h})$. The terminal half-life $\left(\mathrm{t}_{1 / 2}\right)$ of fucoxanthinol and amarouciaxanthin $\mathrm{A}$ in the adipose tissue were $16 \cdot 0$ and $25 \cdot 5 \mathrm{~h}$, respectively, although the $t_{1 / 2}$ in the other tissues, and the plasma and erythrocytes were $2 \cdot 5-9.0$ and $2 \cdot 5-10 \cdot 1 \mathrm{~h}$, respectively. Thus, the $t_{1 / 2}$ in the adipose tissue was 2-fold longer than those of the other tissues.

Table 1. Single-dose oral pharmacokinetic parameters for plasma and erythrocytes of fucoxanthinol $(\mathrm{FxOH})$ and amarouciaxanthin $\mathrm{A}(\mathrm{AxA})^{*}$

\begin{tabular}{|c|c|c|c|c|c|c|c|c|}
\hline & \multicolumn{2}{|c|}{$\mathrm{C}_{\max }(\mathrm{nmol} / \mathrm{l})$} & \multicolumn{2}{|c|}{$T_{\max }(h)$} & \multicolumn{2}{|c|}{$t_{1 / 2}(h)$} & \multicolumn{2}{|c|}{$\mathrm{AUC}_{\infty}(\mathrm{nmol} / \mathrm{l} \times \mathrm{h})$} \\
\hline & $\mathrm{FxOH}$ & $A \times A$ & $\mathrm{FxOH}$ & $A \times A$ & $\mathrm{FxOH}$ & $A \times A$ & $\mathrm{FxOH}$ & $A \times A$ \\
\hline Plasma & 132 & 230 & 4 & 4 & 4.5 & 6.7 & 1430 & 2040 \\
\hline Erythrocytes & $42 \cdot 6$ & $67 \cdot 0$ & 4 & 4 & $9 \cdot 0$ & $7 \cdot 4$ & 352 & 444 \\
\hline
\end{tabular}

$\mathrm{C}_{\max }$, maximum concentration; $\mathrm{T}_{\max }$, time at maximum concentration; $\mathrm{t}_{1 / 2}$, terminal half-life; $\mathrm{AUC} \mathrm{C}_{\infty}$, area under the curve to infinity. * Imprinting Control Region (ICR) mice were orally administrated with fucoxanthin at the dose of $160 \mathrm{nmol} / \mathrm{mouse}$. 
Table 2. Single-dose oral pharmacokinetic parameters for tissues levels of fucoxanthinol $(\mathrm{FxOH})$ and amarouciaxanthin $A$ $(\mathrm{AxA})^{*}$

\begin{tabular}{|c|c|c|c|c|c|c|c|c|}
\hline & \multicolumn{2}{|c|}{$\mathrm{C}_{\max }(\mathrm{nmol} / \mathrm{g})$} & \multicolumn{2}{|c|}{$\mathrm{T}_{\max }(\mathrm{h})$} & \multicolumn{2}{|c|}{$t_{1 / 2}(h)$} & \multicolumn{2}{|c|}{$\mathrm{AUC}_{\infty}(\mathrm{nmol} / \mathrm{g} \times \mathrm{h})$} \\
\hline & $\mathrm{FxOH}$ & $A \times A$ & $\mathrm{FxOH}$ & $A \times A$ & $\mathrm{FxOH}$ & $A \times A$ & $\mathrm{FxOH}$ & $A \times A$ \\
\hline Liver & 584 & 190 & 4 & 4 & 2.5 & 2.5 & 4680 & 1422 \\
\hline Lung & 428 & 180 & 4 & 4 & 5.5 & $5 \cdot 8$ & 3350 & 1060 \\
\hline Kidney & 224 & 102 & 4 & 4 & $6 \cdot 3$ & $10 \cdot 1$ & 1960 & 868 \\
\hline Heart & 229 & 126 & 4 & 4 & 7.5 & 7.4 & 2890 & 1080 \\
\hline Spleen & 249 & 95.5 & 4 & 4 & 3.5 & 3.0 & 1710 & 560 \\
\hline Adipose tissue & $38 \cdot 8$ & $83 \cdot 7$ & 24 & 24 & $16 \cdot 0$ & 25.5 & 1760 & 4630 \\
\hline
\end{tabular}

$\mathrm{C}_{\max }$, maximum concentration; $\mathrm{T}_{\max }$, time at maximum concentration; $\mathrm{t}_{1 / 2}$, terminal half-life; $A \cup \mathrm{C}_{\infty}$, area under the curve to infinity.

*Imprinting Control Region (ICR) mice were orally administrated with fucoxanthin at the dose of $160 \mathrm{nmol} / \mathrm{mouse}$.

The accumulation of fucoxanthin and its metabolites after daily oral administration for 1 week

To examine the accumulation of fucoxanthin and its metabolites, mice were orally administered a mixed micelle containing $160 \mathrm{nmol}$ fucoxanthin for 1 week. During the experiment, the food intake and body-weight gain did not differ between the fucoxanthin-administered mice and the vehicleadministered mice (data not shown). Fig. 2 shows the HPLC chromatogram of the extract from the liver of mice. The peaks at $11.9,13.8$ and $16.4 \mathrm{~min}$ completely fitted the peaks corresponding to the standards for fucoxanthinol, amarouciaxanthin A and fucoxanthin, respectively, when the extract mixed with these standards was injected into the HPLC (data not shown).

Fucoxanthin was detectable in the erythrocytes, liver, lung, kidney, heart, spleen and adipose tissues, but not in the plasma (Fig. 4). The amount of fucoxanthin was $23.1 \mathrm{nmol} / \mathrm{g}$ in the adipose tissue, $20.1 \mathrm{nmol} / \mathrm{g}$ in the heart and $15.1 \mathrm{nmol} / \mathrm{g}$ in the liver (Fig. 4 (B)). Fucoxanthinol and amarouciaxanthin A were distributed in all of the tissues (Fig. 4 (B)), as well as in the plasma and erythrocytes (Fig. 4 (A)). The amount of fucoxanthinol was $123 \mathrm{nmol} / \mathrm{g}$ in the heart, $85.2 \mathrm{nmol} / \mathrm{g}$ in the lung and $83.2 \mathrm{nmol} / \mathrm{g}$ in the liver. Amarouciaxanthin A in the adipose tissue and plasma was distributed at a concentration of $97.5 \mathrm{nmol} / \mathrm{g}$ and $82.0 \mathrm{nmol} / 1$, respectively, higher than the equivalent concentrations of fucoxanthin and fucoxanthinol.

\section{Discussion}

In the present study, the metabolism, distribution and accumulation of dietary fucoxanthin and its metabolites were investigated. When mice were given daily administrations, amarouciaxanthin A accumulated in the adipose tissue (Fig. 4), while fucoxanthinol accumulated in the other tissues. The percentage of fucoxanthin, fucoxanthinol and amarouciaxanthin A to the sum of all of these in the adipose tissue was estimated from the data shown in Fig. 4 as 13, 32 and $55 \%$, respectively, while the percentage in the other tissues was $1-11,63-76$ and $20-26 \%$, respectively. Thus, the accumulation ratios of fucoxanthinol and amarouciaxanthin $\mathrm{A}$ in the adipose tissue were different from those in the other tissues. The present study demonstrated that dietary fucoxanthin preferentially accumulates as amarouciaxanthin $\mathrm{A}$ in the adipose tissue and as fucoxanthinol in the other tissues tested in the study.

A previous study demonstrated that fucoxanthin was undetectable because it is metabolised in the gastrointestinal tract and is absorbed into the body as its metabolite, fucoxanthinol $^{(25)}$. However, the daily oral administration of
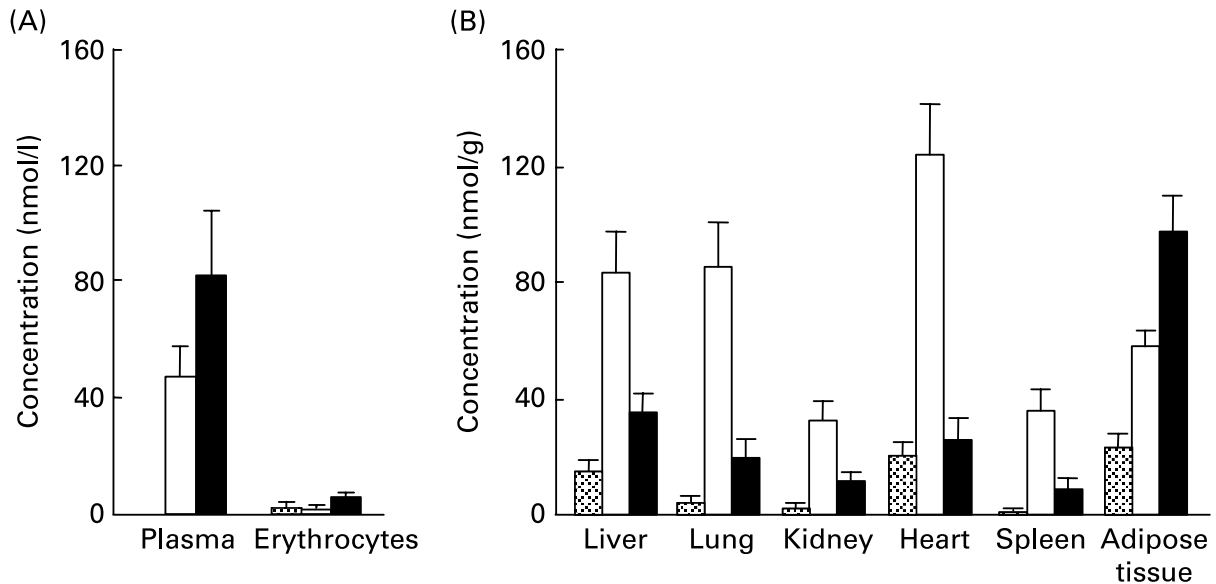

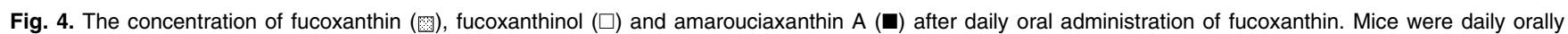
administered with mixed micelles containing fucoxanthin $(160 \mathrm{nmol} /$ mouse) for 1 week. The concentration of fucoxanthin, fucoxanthinol and amarouciaxanthin $A$ in (A) the plasma and erythrocytes and (B) the tissues (liver, lung, kidney, heart, spleen and adipose tissue) was determined by HPLC as described in Experimental methods. Values are means $(n 8)$, with standard errors represented by vertical bars. 
fucoxanthin showed that fucoxanthin was detectable in mice, though the concentration was lower than that of its metabolites (Fig. 4). According to the study using mice or Caco-2 cell monolayers as an intestinal epithelial cell model ${ }^{(25)}$, the appearance of fucoxanthinol in mouse plasma was more rapid compared with Caco- 2 cell monolayers, and this was considered to be due to the presence of pancreatic juice containing lipase, phospholipase and cholesterol esterase. Furthermore, fucoxanthin was detected in the basolateral medium cultured Caco- 2 cell monolayers. These results indicate that fucoxanthin will be absorbed without conversion to fucoxanthinol when the capacity of intestinal hydrolytic activity is over the concentration of dietary fucoxanthin. In the present study, the amount of ingested fucoxanthin would be over the capacity by the daily administrations. A small amount of fucoxanthin seems to be absorbed without being metabolised and degraded, although most of this compound was metabolised and absorbed into the body. This is the first report describing the detection of dietary fucoxanthin accumulation in mammalian tissues. Additionally, when mice were orally given a single administration $(160 \mathrm{nmol})$, the $\mathrm{T}_{\max }$ of fucoxanthinol in the plasma, liver, kidney, heart, lung and spleen was $4 \mathrm{~h}$ (Table 2). On the other hand, the previous study demonstrated that the $\mathrm{T}_{\max }$ was $2 \mathrm{~h}$ in the plasma and liver after a single administration of fucoxanthin $(40 \mathrm{nmol})$. The difference in $T_{\max }$ might be due to the effects of different doses of fucoxanthin on the capacity of intestinal hydrolytic activity.

An epidemiological study ${ }^{(1)}$ has shown that the consumption of brown sea algae is associated with a low risk of breast cancer. Administration of fucoxanthin derived from brown sea algae also showed anti-carcinogenic activity ${ }^{(7,8)}$; for example, our previous study ${ }^{(8)}$ demonstrated that ad libitum administration of $0.5 \%$ fucoxanthin-containing drinking water for 4 weeks suppressed azoxymethane-induced aberrant crypt foci, which is a pre-neoplastic marker for colon cancer. The inhibitory mechanism was considered to cause the induction of apoptosis and cell cycle arrest ${ }^{(9-11)}$, and their effective concentrations were more than $20 \mu \mathrm{M}$. The present study demonstrated that fucoxanthin accumulated after daily oral administration (Fig. 4). However, this concentration seems to be insufficient to exert physiological activities such as the induction of apoptosis and cell cycle arrest. Asai et al. ${ }^{(26)}$ demonstrated the antiproliferative effect of fucoxanthinol and amarouciaxanthin A in prostate cancer PC-3 cells; these half-maximal inhibitory concentration $\left(\mathrm{IC}_{50}\right)$ values were $3 \cdot 0$ and $4.6 \mu \mathrm{M}$, respectively. In the present study, the concentrations of fucoxanthinol and amarouciaxanthin A in plasma were 47 (SE 10) and 82 (SE 22) nmol/l, respectively (Fig. 4), and they were lower than the $\mathrm{IC}_{50}$ values. However, these metabolites may exert their antiproliferative effects additively or synergistically in vivo. Thus, the fucoxanthin metabolites fucoxanthinol and amarouciaxanthin A could be associated with the anti-carcinogenic activity of fucoxanthin.

The $\mathrm{AUC}_{\infty}$ of fucoxanthinol and amarouciaxanthin $\mathrm{A}$ in the plasma was 1430 and $2040 \mathrm{nmol} / \mathrm{l} \times \mathrm{h}$, respectively, after an oral administration of $160 \mathrm{nmol}$ fucoxanthin (Table 1). The previous study demonstrated that the $\mathrm{AUC}_{\infty}$ of astaxanthin, one of the xanthophylls, in plasma was $2260 \mathrm{nmol} / \mathrm{l} \times \mathrm{h}$ after an oral administration of astaxanthin (approximately $67 \mu \mathrm{mol})^{(22)}$. The $\mathrm{AUC}_{\infty}$ represented the absorbed amounts of fucoxanthin and astaxanthin, suggesting that the ratio of absorbed fucoxanthin metabolites to the dose was greater than that of astaxanthin. The present study demonstrated that the accumulating tissues for fucoxanthinol were the liver and heart, and that for amarouciaxanthin A was the adipose tissue. On the other hand, astaxanthin was accumulated in the spleen, kidney and adrenal gland in animals greater than in the liver, lung and heart after ad libitum intake of a diet containing $3 \%(\mathrm{w} / \mathrm{w})$ astaxanthin for $14 \mathrm{~d}$ in rats ${ }^{(21)}$. In addition, this study also showed that the amount of astaxanthin in the spleen was 10-fold higher than that in the liver. Thus, the accumulating tissue and concentration seem to depend on the type of xanthophyll. This indicates that the bioavailability of fucoxanthin (and its metabolites) may be higher than that of other xanthophylls, at least of astaxanthin.

It was reported that fucoxanthinol is converted to amarouciaxanthin A by short-chain dehydrogenase/reductase in the liver ${ }^{(26)}$. After daily oral administration of fucoxanthin, the ratio of amarouciaxanthin A in the liver was almost similar to that in other tissues except for the adipose tissue, in which the ratio was the highest among all the tissues tested (Fig. 4). Fucoxanthinol would be converted to amarouciaxanthin A by short-chain dehydrogenase/reductase in the liver and rapidly transported to the other tissues. On the other hand, fucoxanthinol and amarouciaxanthin A were detectable in the adipose tissue but not in the other tissues $24-72 \mathrm{~h}$ after the single oral administration of fucoxanthin (Fig. 3). Fucoxanthinol accumulated in the adipose tissues might be slowly converted to amarouciaxanthin $\mathrm{A}$ in this tissue. These results indicated that most of the fucoxanthinol was metabolised to amarouciaxanthin $\mathrm{A}$ in the liver within $24 \mathrm{~h}$ after the administration, and some of the fucoxanthinol was accumulated and slowly metabolised to amarouciaxanthin $A$ in the adipose tissue. To verify this assumption, further studies are needed.

In conclusion, dietary fucoxanthin was mainly converted to fucoxanthinol. Fucoxanthin metabolites were accumulated in the body at a higher ratio than astaxanthin, and were preferentially accumulated in the liver, heart and adipose tissues, suggesting that these tissues are targets of fucoxanthin metabolites.

\section{Acknowledgements}

This research was supported by the Research and Development Programme for New Bio-industry Initiatives (20062010) of the Bio-oriented Technology Research Advancement Institution (BRAIN), Japan.

T. H., M. M. and K. K. contributed to the design of the study and prepared the paper. Y. O., M. T. and K. Y. performed the animal experiments and analytical work. Y. O., M. T., S. K. D. and T. M. purified fucoxanthin, fucoxanthinol and amarouciaxanthin $\mathrm{A}$.

The authors declare no conflict of interest.

\section{References}

1. Teas $\mathbf{J}$ (1983) The dietary intake of Laminaria, a brown seaweed, and breast cancer prevention. Nutr Cancer 4, 217-222.

2. Yamamoto I \& Maruyama H (1985) Effect of dietary seaweed preparations on 1,2-dimethylhydrazine-induced intestinal carcinogenesis in rats. Cancer Lett 26, 241-251. 
3. Yamamoto I, Maruyama H \& Moriguchi M (1987) The effect of dietary seaweeds on 7,12-dimethylbenz $[a]$ anthracene-induced mammary tumorigenesis in rats. Cancer Lett 35, 109-118.

4. Funahashi H, Imai T, Mase T, et al. (2001) Seaweed prevents breast cancer? Jpn J Cancer Res 92, 483-487.

5. Funahashi H, Imai T, Tanaka Y, et al. (1999) Wakame seaweed suppresses the proliferation of 7,12-dimethylbenz $(a)$ anthraceneinduced mammary tumors in rats. Jpn J Cancer Res 90, 922-927.

6. Haugan JA, Aakermann T \& Liaaen-Jensen S (1992) Isolation of fucoxanthin and peridinin. Methods Enzymol 213, 231-245.

7. Okuizumi J, Takahashi T, Yamane T, et al. (1993) Inhibitory effects of fucoxanthin, a natural carotenoid, on $N$-ethyl$N^{\prime}$-nitro- $N$-nitrosoguanidine-induced mouse duodenal carcinogenesis. Cancer Lett 68, 159-168.

8. Das SK, Hashimoto T, Baba M, et al. (2006) Japanese kelp (kombu) extract suppressed the formation of aberrant crypt foci in azoxymethane challenged mouse colon. J Clin Biochem Nutr 38, 119-125.

9. Kotake-Nara E, Kushiro M, Zhang H, et al. (2001) Carotenoids affect proliferation of human prostate cancer cells. J Nutr 131, 3303-3306.

10. Hosokawa M, Kudo M, Maeda H, et al. (2004) Fucoxanthin induces apoptosis and enhances the antiproliferative effect of the PPAR $y$ ligand, troglitazone, on colon cancer cells. Biochim Biophys Acta 1675, 113-119.

11. Das SK, Hashimoto T, Shimizu K, et al. (2005) Fucoxanthin induces cell cycle arrest at $\mathrm{G}_{0} / \mathrm{G}_{1}$ phase in human colon carcinoma cells through up-regulation of $\mathrm{p} 21^{\mathrm{WAF} 1 / \mathrm{Cip} 1}$. Biochim Biophys Acta 1726, 328-335.

12. Shiratori K, Ohgami K, Ilieva I, et al. (2005) Effects of fucoxanthin on lipopolysaccharide-induced inflammation in vitro and in vivo. Exp Eye Res 81, 422-428.

13. Maeda H, Hosokawa M, Sashima T, et al. (2006) Fucoxanthin and its metabolite, fucoxanthinol, suppress adipocyte differentiation in 3T3-L1 cells. Int J Mol Med 18, 147-152.

14. Maeda H, Hosokawa M, Sashima T, et al. (2005) Fucoxanthin from edible seaweed. Undaria pinnatifida, shows antiobesity effect through UCP1 expression in white adipose tissues. Biochem Biophys Res Commun 332, 392-397.

15. Budowski P, Ascarelli I, Gross J, et al. (1963) Provitamin $\mathrm{A}_{2}$ from lutein. Science 142, 969-971.

16. Oshima $S$, Inakuma $T \&$ Narisawa $T$ (1999) Absorption and distribution of lycopene in rat colon. J Nutr Sci Vitaminol 45, $129-134$
17. Schweigert FJ, Buchholz I, Schuhmacher A, et al. (2001) Effect of dietary $\beta$-carotene on the accumulation of $\beta$-carotene and vitamin A in plasma and tissues of gilts. Reprod Nutr Dev 41, 47-55.

18. Poor CL, Bierer TL, Merchen NR, et al. (1993) The accumulation of $\alpha$ - and $\beta$-carotene in serum and tissues of preruminant calves fed raw and steamed carrot slurries. J Nutr 123, 1296-1304.

19. Parker RS (1996) Absorption, metabolism, and transport of carotenoids. FASEB J 10, 542-551.

20. Rock CL (1997) Carotenoids: biology and treatment. Pharmacol Ther 75, 185-197.

21. Petri D \& Lundebye AK (2007) Tissue distribution of astaxanthin in rats following exposure to graded levels in the feed. Comp Biochem Physiol C Toxicol Pharmacol 145, 202-209.

22. Merke Odeberg J, Lignell $\AA$, Pettersson A, et al. (2003) Oral bioavailability of the antioxidant astaxanthin in humans is enhanced by incorporation of lipid based formulations. Eur $J$ Pharm Sci 19, 299-304.

23. Showalter LA, Weinman SA, Østerlie M, et al. (2004) Plasma appearance and tissue accumulation of non-esterified, free astaxanthin in C57BL/6 mice after oral dosing of a disodium disuccinate diester of astaxanthin (Heptax $\left.{ }^{\mathrm{TM}}\right)$. Comp Biochem Physiol C Toxicol Pharmacol 137, 227-236.

24. World Health Organization (1996) Toxicological Evaluation of Certain Food Additives and Contaminants in Food. Joint FAO/WHO Expert Committee on Food Additives. WHO Food Additive Series no. 35. Geneva: WHO.

25. Sugawara T, Baskaran V, Tsuzuki W, et al. (2002) Brown algae fucoxanthin is hydrolyzed to fucoxanthinol during absorption by Caco-2 human intestinal cells and mice. J Nutr 132, 946-951.

26. Asai A, Sugawara T, Ono H, et al. (2004) Biotransformation of fucoxanthinol into amarouciaxanthin $\mathrm{A}$ in mice and HepG2 cells: formation and cytotoxicity of fucoxanthin metabolites. Drug Metab Dispos 32, 205-211.

27. Asai A, Yonekura L \& Nagao A (2008) Low bioavailability of dietary epoxyxanthophylls in humans. Br J Nutr 100, 273-277.

28. Antia NJ (1965) The optical activity of fucoxanthin. Can J Chem 43, 302-303.

29. Matsuno T, Ookubo M \& Komori T (1985) Carotenoids of tunicates, III. The structural elucidation of two new marine carotenoids, amarouciaxanthin A and B. J Nat Prod 48, 606-613.

30. Tabata K, Yamaoka K, Kaibara A, et al. (1999) Moment analysis program available on Microsoft Excel. Xenobiot Metab Dispos 14, 286-293. 